\title{
Apoptosis-associated uncoupling of bone formation and resorption in osteomyelitis
}

\author{
lan Marriott* \\ Department of Biology, University of North Carolina at Charlotte, Charlotte, NC, USA
}

Edited by:
Yongqun "Oliver" He, Virginia Tech, USA

Reviewed by:

Glen C. Ulett, Griffith University, Australia

George Hajishengallis, University of Pennsylvania, USA

*Correspondence:

lan Marriott, Department of Biology,

University of North Carolina at

Charlotte, 9201 University City

Boulevard, Charlotte, NC 28223,

USA

e-mail:imarriot@uncc.edu
The mechanisms underlying the destruction of bone tissue in osteomyelitis are only now being elucidated. While some of the tissue damage associated with osteomyelitis likely results from the direct actions of bacteria and infiltrating leukocytes, perhaps exacerbated by bacterial manipulation of leukocyte survival pathways, infection-induced bone loss predominantly results from an uncoupling of the activities of osteoblasts and osteoclasts. Bacteria or their products can directly increase osteoclast formation and activity, and the inflammatory milieu at sites of infection can further promote bone resorption. In addition, osteoclast activity is critically regulated by osteoblasts that can respond to bacterial pathogens and foster both inflammation and osteoclastogenesis. Importantly, bone loss during osteomyelitis is also brought about by a decline in new bone deposition due to decreased bone matrix synthesis and by increased rates of osteoblast apoptosis. Extracellular bacterial components may be sufficient to reduce osteoblast viability, but the causative agents of osteomyelitis are also capable of inducing continuous apoptosis of these cells by activating intrinsic and extrinsic cell death pathways to further uncouple bone formation and resorption. Interestingly, bacterial internalization appears to be required for maximal osteoblast apoptosis, and cytosolic inflammasome activation may act in concert with autocrine/paracrine death receptor-ligand signaling to induce cell death. The manipulation of apoptotic pathways in infected bone cells could be an attractive new means to limit inflammatory damage in osteomyelitis. However, the mechanism that is the most important in bacterium-induced bone loss has not yet been identified. Furthermore, it remains to be determined whether the host would be best served by preventing osteoblast cell death or by promoting apoptosis in infected cells.

Keywords: osteomyelitis, apoptosis, osteoblasts, osteoclasts, inflammation, osteoimmunology, bacterial infection

\section{INTRODUCTION}

Osteomyelitis is a severe infection of bone tissue that is associated with significant morbidity and typically leads to bone resorption, dysfunction, and progressive inflammatory destruction (Sax and Lew, 1999). Such infections are characterized in rodent models by the rapid production of inflammatory mediators, followed by infiltration of leukocytes at 3-7 days after infection, and subsequent bone resorption and adjacent areas of new bone deposition at 14-28 days (Yoshii et al., 2002). Staphylococcus aureus and Salmonella spp. are the most common causative agents of osteomyelitis. S. aureus accounts for approximately $80 \%$ of all osteomyelitis cases (Lew and Waldvogel, 2004; Labbé et al., 2010) while Salmonella species represent one of the most serious pathogens of bone in sickle cell patients and immunosuppressed patients (Anand and Glatt, 1994; Workman et al., 1996; Koehler et al., 1998; Overturf, 1999). S. aureus has a propensity to colonize broken skin and so a history of trauma or skin infection is a significant risk factor for bone and joint infections caused by this organism (Barton et al., 1987; Dubey et al., 1988). The majority of bone infections in children are caused by hematogenous spread of bacteria from distant infection foci through the bloodstream, while most cases in adults result from external sources such as post-traumatic wounds and post-operative infections (Mousa,
2003; De Boeck, 2005). Indeed, implant-related infection is such a feared complication in orthopedic surgery that perioperative administration of antibiotics is routinely used to reduce this risk (Davis, 2005). However, despite prophylaxis and improvements in the diagnosis of osteomyelitis, the incidence and severity of these bone infections appear to be increasing (Jensen et al., 1997; Arnold et al., 2006).

While osteomyelitis is associated with progressive inflammatory tissue destruction, such infections also result in marked bone resorption at sites of infection and proximal abnormal bone formation. The continual process of bone remodeling requires the coordinated regulation of the genesis and activity of osteoblasts and osteoclast lineages. Osteoclasts drive the resorption of bone by acidification and release of lysosomal enzymes (Teitelbaum et al., 1997). In contrast, osteoblasts produce components of bone, principally type I collagen, and catalyze the calcification process. As such, any interference with these integrated cell types can result in abnormal bone remodeling. Bacteria such as S. aureus and their products can be potent stimulators of resorptive bone loss (Nair et al., 1995, 1996). While bacteria can directly damage bone by producing acids and proteases, they can also stimulate osteoclastogenesis. For example, the site of infection in animal models of $S$. aureus osteomyelitis contains high 
numbers of macrophages and osteoclasts (Wiggers et al., 2011), and S. aureus surface-associated proteins can stimulate osteoclast formation and activity (Meghji et al., 1998; Lau et al., 2006). Similarly, systemically administered lipopolysaccharide (LPS) or local application of LPS derived from Aggregatibacter actinomycetemcomitans can reduce bone volume (Ochi et al., 2010; Madeira et al., 2013) and macrophages and osteoclast-like cells respond to this Gram-negative bacterial product by releasing cytokines and nitric oxide (NO) (Wiggers et al., 2011). However, it is unclear whether such effects are due to a direct action on osteoclasts and/or their progenitors, or are secondary to the production of other mediators, such as inflammatory cytokines, which modulate osteoclast formation and activity (Meghji et al., 1998).

Importantly, it is becoming increasingly apparent that, in addition to increased osteolysis and direct inflammatory degradation of bone matrix, tissue damage during osteomyelitis progression is associated with significant bone cell death. Again, cultured macrophages and osteoclasts can respond to LPS and $S$. aureus by releasing factors such as $\mathrm{NO}$ that can promote cell death (Wiggers et al., 2011). Importantly, osteonecrosis of the jaw is characterized by high-grade inflammation and large lesions coupled with osteocyte apoptosis (Lesclous et al., 2009). The death of this cell type is especially important given that this bone matrix embedded cell type regulates the bone remodeling activities of bone surface osteoclasts and osteoblasts via the lacuna-canaliculi network (as discussed in Matsuo, 2009). Furthermore, apoptotic cells accompany trabecular osteolysis in porcine models of osteomyelitis, in a similar manner to that typically observed in osteomyelitic lesions in following hematological S. aureus spread (Jensen et al., 2010). In the present review, we provide an overview of the mechanisms that can directly or indirectly induce bone cell death following infection and we discuss the possible significance of modulated programmed cell death in the progression of osteomyelitis.

\section{ROLE OF RESIDENT BONE CELLS IN INFLAMMATORY BONE LOSS ASSOCIATED WITH OSTEOMYELITIS}

Current treatment for osteomyelitis involves expensive and prolonged (even lifelong) parenteral antibiotic treatment, surgically debridement of necrotic bone, and often amputation. While these strategies are effective in reducing or eliminating the ability to isolate culturable bacteria from affected tissue, osteomyelitis is often refractory with a recent retrospective study revealing that a bacteriological cure was not achieved in up to $17 \%$ of cases (Priest and Peacock, 2005). Possible explanations for this persistence include the increasing incidence of antibiotic resistance in S. aureus and Salmonella spp. (Workman et al., 1996; Heseltine, 2000), with the appearance of isolates that are even resistant (Boneca and Chiosis, 2003) or less susceptible (Tenover et al., 2001) to vancomycin, and the formation of staphylococcal bacterial biofilms that may render these organisms less susceptible to host immune attack (as reviewed in Brady et al., 2008; Hanke and Kielian, 2012). However, recent in vitro studies have demonstrated that neutrophils can recognize biofilms and respond by phagocytosis and release of lactoferrin, elastase, and DNA suggesting that staphylococcal biofilms are not inherently resistant to neutrophil-mediated destruction, although it remains to be determined how effectively these cells attack biofilms in vivo (Meyle et al., 2010). Furthermore, these explanations fail to fully account for the observation that up to $50 \%$ of "cured" osteomyelitis cases display infection-related sequelae. Indeed, patients can have recurrent attacks of osteomyelitis following the completion of treatment regimens even when causative organisms can no longer be isolated from infection sites (Priest and Peacock, 2005).

An alternative explanation for these phenomena may lie in the ability of the causative agents of osteomyelitis to invade and reside within resident bone cells. An intracellular lifestyle provides advantages to a variety of microbes that include access to host cell metabolites (as discussed in Ray et al., 2009; Wright and Nair, 2010; Friedrich et al., 2012). Importantly, internalization also provides a means of protection against neutrophil and antibody-mediated immune responses, and mitigates therapeutic interventions by limiting exposure to antibiotics. Salmonella species are intracellular bacterial pathogens and this organism is recognized to invade epithelial cells (Rosenshine et al., 1994; Jones and Falkow, 1996; Ohl and Miller, 2001). Importantly, we have demonstrated that this bacterium can invade primary osteoblasts (Bost et al., 2000). In contrast, staphylococci have traditionally been regarded as non-invasive pathogens that damage host bone cells after adhering to the extracellular matrix (Nair et al., 1996). However, it is becoming increasingly apparent that these organisms can be internalized by cultured osteoblasts and can persist intracellularly (Hudson et al., 1995; Ellington et al., 1999, 2003, 2006; Jevon et al., 1999; Ahmed et al., 2001). Osteoblasts appear to be active in this invasion process as evidenced by the requirement that these cells, but not bacteria, be alive for internalization to occur (Hudson et al., 1995; Ellington et al., 1999). Furthermore, reorganization of the osteoblast cytoskeleton and receptor-mediated endocytosis are utilized in the internalization process (Ellington et al., 1999; Jevon et al., 1999). It is important to note that bacteria released following lysis or trypsinization of S. aureus-containing human osteoblasts are viable and are capable of invading other osteoblasts (Ellington et al., 2003). In addition, significant time-dependent changes in the structure of $S$. aureus can occur after as little as $12 \mathrm{~h}$ exposure to an intracellular environment that render the organisms less sensitive to antibiotics capable of penetrating eukaryotic cells (Ellington et al., 2006). Interestingly, the ability of bacteria to invade osteoblasts may also direct the ability of this organism to form biofilms and it has been suggested that invasion promotes a biofilm-like surface on S. aureus that correlates with antibiotic resistance (Brady et al., 2008). As such, these host evasion mechanisms may be intimately related (Brady et al., 2008). Such findings may explain why antibiotic treatment can reduce the number of viable bacteria in animal models of staphylococcal osteomyelitis but does not reliably sterilize infected bone (Monzón et al., 2001). Bacteria sequestered inside the osteoblast may therefore provide a reservoir of bacteria and contribute to recurrent chronic osteomyelitis that often occurs despite the presence of antibiotics and a seemingly adequate humoral response (Lew and Waldvogel, 2004).

In addition to the synthesis of new bone matrix, osteoblasts produce soluble factors that regulate the formation and activity of osteoclasts. For example, osteoblasts are an important source of receptor activator of NF-kB ligand (RANKL) and osteoprotegerin 
(OPG), critical regulators of osteoclast development and function (Wada et al., 2006). RANKL interacts with its receptor RANK on osteoclast progenitor cells and plays a central role in promoting osteoclast formation and activity (Hsu et al., 1999; Kong et al., 1999a,b; Kim et al., 2000; Li et al., 2000; Wada et al., 2006). In contrast, OPG functions as a decoy receptor for RANKL and limits osteoclastogenesis (Wada et al., 2006). Interestingly, causative agents of periodontal infections such as Porphyromonas gingivalis have been found to induce the RANKL expression in osteoblasts (Okahashi et al., 2004) and elevated levels of this molecule have been found in osteomyelitis-associated bone lesions (Montonen et al., 2006). While such RANKL production may be attributable to the activity of resident bone cells, it should be noted that activated T-lymphocytes also produce this cytokine (Anderson et al., 1997; Horwood et al., 1999; Hsu et al., 1999). RANKL production by osteoblasts and T-cells can be stimulated by the inflammatory cytokines interleukin (IL) $1 \beta$ and tumor necrosis factor- $\alpha$ TNF- $\alpha$ (Walsh and Choi, 2003) that are detectable in infected bone tissues of osteomyelitis patients (O'Keefe et al., 1997). In addition, both of these inflammatory mediators have been demonstrated to concomitantly depress OPG expression in osteoblasts and we have shown that $S$. aureus challenge similarly inhibits osteoblast production of this RANKL decoy receptor (Young et al., 2011). This then provides another mechanism that can favor bone resorption at sites of infection. Finally, Choi et al. (2005) have shown that cyclooxygenase-2 (COX2) inhibitors can inhibit P. gingivalis-induced RANKL expression by osteoblasts and restore OPG levels. This observation is in agreement with our own recent studies demonstrating that $S$. aureus elevates RANKL production by osteoblasts and this effect is similarly abolished by a specific COX2 inhibitor (Somayaji et al., 2008). These findings suggest that osteoblasts produce PGE2 that acts in a paracrine or autocrine manner to induce RANKL release and limit OPG production, creating a microenvironment that favors bone resorption (Choi et al., 2005). Together, these data suggest that bacterially challenged osteoblasts can promote the formation and activity of osteoclasts leading to a net loss of bone at sites of infection (as summarized in Figure 1).

But the activities of osteoblasts may not be limited to the synthesis of bone matrix components and the regulation of osteoclast activity. There is increasing evidence that osteoblasts may directly contribute to inflammation in infected bone tissue. Studies from our group and others have demonstrated that isolated osteoblasts utilize members of the toll-like receptor (TLR) and nucleotidebinding oligomerization domain-containing (NOD)-like receptor (NLR) families of innate immune receptors to detect the presence of microbial products (Gasper et al., 2002; Madrazo et al., 2003; Marriott et al., 2005; Chauhan and Marriott, 2010) (Figure 1). The activation of these sensors precipitates transcription factor activation and leads to the release of inflammatory cytokines and the expression of cell surface antigen presenting and co-stimulatory molecules (Barton and Medzhitov, 2003). Consistent with this observation, our in vitro studies show that $S$. aureus is a potent stimulus for the production of soluble and cell surface molecules by isolated osteoblasts that could play key roles in the initiation and/or progression of inflammatory immune responses (Marriott, 2004). Such molecules include

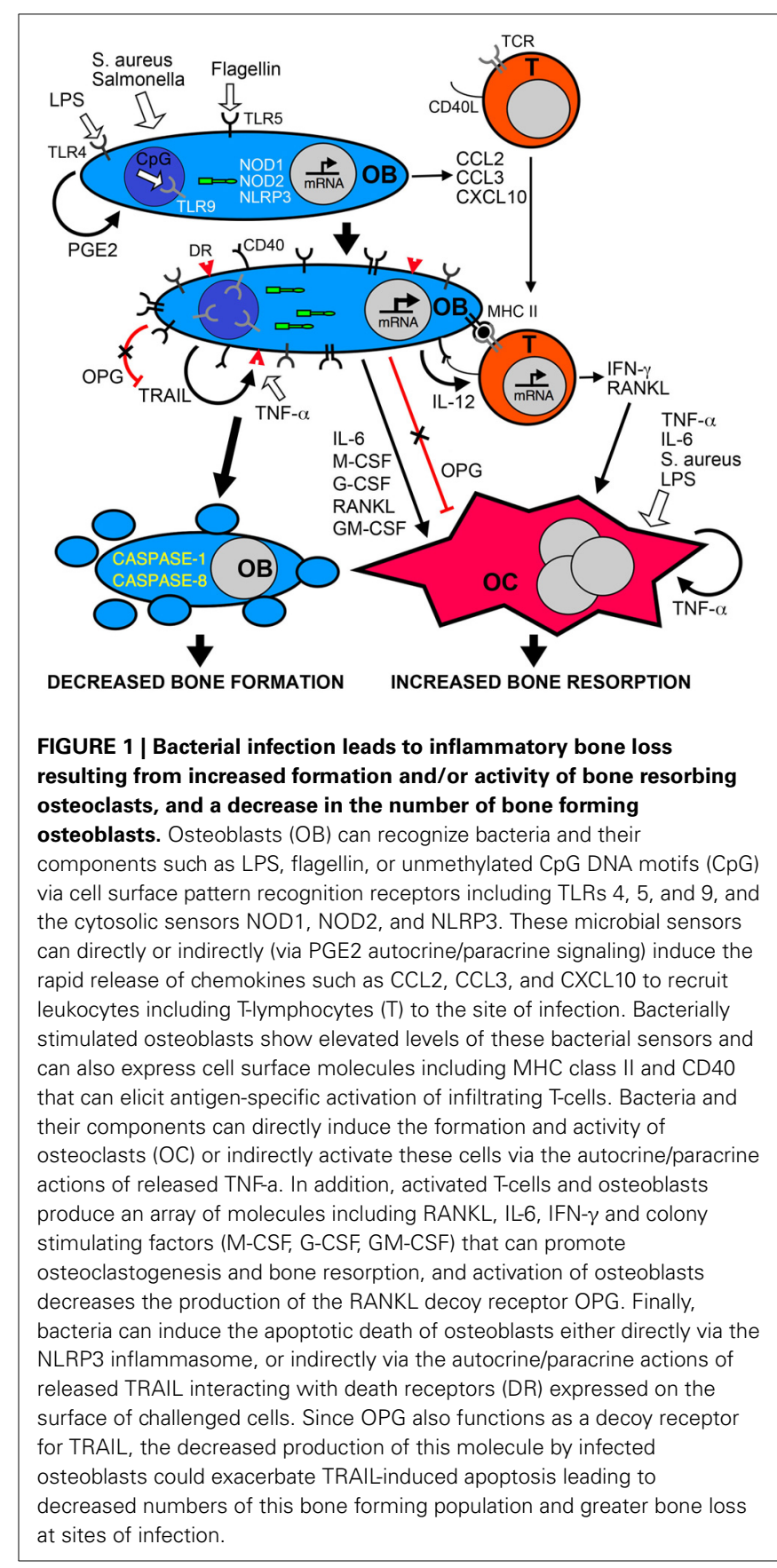

CXCL10 (Gasper et al., 2002) and CCL2 (Bost et al., 2001) that are potent chemoattractants for T-cells and macrophages, leukocytes frequently observed in bone tissue following infection (Stashenko et al., 1992; Bremell et al., 1994), and IL-6 (Bost et al., 1999) an often inflammatory cytokine that can directly or indirectly modulate the activity of bone-resorptive osteoclasts (Lowik et al., 1989; Ishimi et al., 1990; de la Mata et al., 1995; Greenfield et al., 1995; Hofbauer and Heufelder, 1996). Furthermore, our laboratory has demonstrated that primary osteoblasts can produce growth factors such as granulocyte macrophage colony stimulating factor (GM-CSF), macrophage colony stimulating factor 
(M-CSF) and granulocyte colony stimulating factor (G-CSF) following S. aureus exposure (Bost et al., 2000) that could increase osteoclastogenesis and promote bone resorption (Lorenzo et al., 1987; Kodama et al., 1991; Takahashi et al., 1991; Liggett et al., 1993; Povolny and Lee, 1993), and augment immune responses to this bacterial pathogen (Frenck et al., 1990; Freund and Kleine, 1992; Dale, 1995). As such, the production of these mediators by bacterially challenged osteoblasts may significantly contribute to involucrum and sequestrum formation during osteomyelitis, and exacerbate damaging inflammation.

\section{MODULATION OF LEUKOCYTE APOPTOSIS IN OSTEOMYELITIS}

The interaction between Salmonella species and host cell types often results in the death of mammalian cells but these bacteria appear to do so by host cell-type specific mechanisms (as reviewed in Fink and Cookson, 2007) and the mechanisms underlying host cell death by such Gram-positive bacterial pathogens have been extensively reviewed elsewhere (Ulett and Adderson, 2006). While Salmonella induces apoptosis in epithelial cells, invasion of macrophages rapidly triggers caspase-1-dependent programmed cell death, or pyroptosis, in a salmonella pathogenicity island-1 type III secretion system and flagella dependent manner (Fink and Cookson, 2007). Since caspase-1-deficient mice are more susceptible to salmonellosis, such pyroptotic death has generally been considered to be a protective response to infection (Fink and Cookson, 2007). In contrast, Brucella abortus, an intracellular zoonotic pathogen that causes osteomyelitis in humans, elicits host macrophage apoptosis following invasion (Cha et al., 2013). However, apoptosis only occurs after a period of bacterial replication and so such cell death appears to favor the pathogen by eliminating immune cells. Furthermore, it should be noted that some Gram-positive pathogens of bone including streptococci also show a capacity to escape in a viable form from macrophages in an NO-dependent manner (Ulett and Adderson, 2005).

While several causative agents of osteomyelitis can induce programmed cell death of infiltrating macrophages, delayed neutrophil apoptosis is a characteristic feature of human osteomyelitis arising from either Gram-negative or Gram-positive organisms (as discussed in Ocaña et al., 2008). Neutrophils from osteomyelitis patients exhibit less spontaneous apoptosis than that seen in cells from healthy donors (Asensi et al., 2004). Interestingly, the serum of osteomyelitis patients has been found to significantly reduce apoptosis rates over a $12 \mathrm{~h}$ time period in isolated neutrophils (Asensi et al., 2004). This effect has been attributed to the elevated IL- 6 levels seen in patient's sera as these anti-apoptotic effects could be reversed with IL-6 neutralizing antibodies or mimicked with exogenous IL-6 (Asensi et al., 2004). Such cytokine-induced neutrophil apoptosis inhibition has been demonstrated following infection with the Grampositive organism, S. aureus, or the Gram-negative bacterium, Escherichia coli, and has also been observed following challenge with lipoteichoic acid (LTA) or LPS, bacterial ligands for TLR2 and TLR4 pattern recognition receptors, respectively (Ocaña et al., 2008). This auto-induced reduction in neutrophil apoptosis correlates with an altered ratio of pro-apoptotic B-cell lymphoma $(\mathrm{Bcl}) 2$-associated X protein (Bax) to anti-apoptotic Bcl-extra large (Bcl- $\mathrm{xL})$ expression in these cells, and this is notable since the loss-of-function Bax promoter polymorphism A allele has been found to be more frequent in osteomyelitis patients (Ocaña et al., 2008). The neutrophils in such patients express less Bax and, accordingly, lower rates of apoptosis. Similarly, polymorphisms in the gene encoding TLR4, but not TLR2, have been identified as risk factors for chronic Gram-negative bacterial osteomyelitis (Montes et al., 2006). Neutrophils isolated from osteomyelitis patients with TLR4 polymorphisms show less LPS-induced activation of the key pro-inflammatory transcription factor NF-kB, reduced IL-6 production, and a lower induced reduction in apoptosis (Montes et al., 2006). It is conceivable that inflammatory cytokine-induced lengthening of neutrophil lifespan represents an attempt by the host to augment bacterial killing at the site of infection. However, limiting leukocyte apoptosis in this manner may ultimately be detrimental to the host due to the exacerbation of inflammatory damage (Ocaña et al., 2007).

\section{MODULATION OF OSTEOCLAST FORMATION AND SURVIVAL IN OSTEOMYELITIS}

While bacteria or their products can directly destroy bone tissue, they can also indirectly elicit bone loss by increasing the formation and function of bone-resorbing osteoclasts (Chung et al., 2006; Maruyama et al., 2006). Indeed, osteoclast responses in S. aureus-infected tissue differ markedly from those seen in sterile bone trauma in that these cells behave as acute inflammatory responders with substantial activity at the margins of the infected site and adjacent uninjured tissue (Pesanti and Lorenzo, 1998). Osteoclastogenesis and osteoclast activity can be up-regulated by soluble mediators produced by infiltrating leukocytes such as macrophages and neutrophils. For example, the capsular-like polysaccharide antigen of A. actinomycetemcomitans, an organism implicated in juvenile periodontitis, stimulates the production of IL-1 $\alpha$ that, in turn, promotes osteoclast formation and bone resorption (discussed in Yamamoto et al., 1999). Similarly, surface-associated material extracted from S. aureus has been shown to stimulate osteoclastogenesis and pit formation on dentine slices in a TNF- $\alpha$ and IL- 6 dependent manner (Meghji et al., 1998). Such induction by cytokines generally considered to be inflammatory could, in part, explain the large numbers of osteoclasts that are typically associated with infarcted bone in osteomyelitis.

However, the formation and bone resorbing functions of osteoclasts are regulated in large part by osteoblasts and a substantial body of evidence has accumulated to show that bacterially challenged osteoblasts produce an array of soluble mediators that can promote osteoclastogenesis and osteoclast activity (as summarized in Figure 1). Recently, Gram-negative bacterial LPS has been demonstrated to induce osteoclastogenesis and reduce bone volume following in vivo administration, and this effect was blocked by co-administration of OPG (Ochi et al., 2010). While most cultured mononuclear osteoclasts die within $24 \mathrm{~h}$ in the absence of stimuli, both RANKL and bacterial LPS support survival and induce differentiation into multinuclear cells, providing a potential mechanism underlying LPS-induced bone loss (Suda et al., 2002). Such an effect does not appear to be limited to Gram-negative bacterial products, as S. aureus binding to 
osteoblasts can induce the release of soluble RANKL by these cells (Widaa et al., 2012). Furthermore, biofilm components from a clinical S. aureus strain have recently been demonstrated to induce osteoblast RANKL production and increase the RANKL/OPG ratio in culture media (Sanchez et al., 2013). In particular, staphylococcus protein $\mathrm{A}(\mathrm{SpA})$ has been reported to bind to TNF receptor 1 (TNFR1) on osteoblasts (Claro et al., 2013), and S. aureus-induced increases in osteoblast RANKL expression are not seen with SpA mutants (Claro et al., 2011). However, one study suggests that $S$. aureus surface-associated material can promote osteoclast formation in vitro in a RANKL independent manner (Lau et al., 2006), while another indicates that LPSinduced bone resorption can occur independent of RANKL or the inflammatory mediators IL-1 $\beta$ or TNF- $\alpha$ (Suda et al., 2002). As such, it is possible that bacterial products can have both direct and indirect effects on osteoclast activity in inflammatory bone loss.

It is important to note that some bacterial pathogens appear to manipulate bone homeostasis in a species-specific manner. For example, $P$. gingivalis culture products including hemoglobin receptor protein can suppress RANKL-induced in vitro osteoclastogenesis (Fujimura et al., 2006). It seems likely that differences in the manipulation of bone tissue reflect distinct bacterial survival and/or dissemination strategies. While net resorption of bone may favor S. aureus and Salmonella infections, rapid and extensive destruction of alveolar bone would be anticipated to result in tooth loss and the elimination of the gingival crevice that is an anatomical niche for periodontal pathogens such as $P$. gingivalis. A suppressive effect of this organism on osteoclastogenesis may, therefore, permit chronic infection (Fujimura et al., 2006).

\section{INDUCTION OF APOPTOSIS IN BONE FORMING OSTEOBLASTS DURING OSTEOMYELITIS}

In addition to the increased formation and activity of bone resorbing osteoclasts in osteomyelitis, inflammatory bone loss may also result from the elimination of the cells responsible for new bone matrix deposition following infection. In support of this notion, reduced expression of markers associated with differentiated osteoblasts including alkaline phosphatase activity, collagen type I production, and mineralized nodules, is seen in alveolar bone tissue from patients with periodontal disease (Mori et al., 2007). Importantly, work from our laboratory and our collaborators have demonstrated that bone-forming osteoblasts undergo apoptotic cell death following infection with the principle causative agents of osteomyelitis, S. aureus and Salmonella (Tucker et al., 2000; Alexander et al., 2003). We have shown that Salmonella enterica can elicit significant apoptotic cell death as rapidly at $24 \mathrm{~h}$ post-infection. Interestingly, we have found that intracellular invasion is required for maximal induction of apoptosis in osteoblasts as evidenced by the sensitivity of this response to a pharmacological inhibitor of endocytosis and a significantly smaller apoptotic response in this cell type to invasion deficient Salmonella strains (Marriott et al., 2005; McCall et al., 2008). As such, inflammatory bone loss during osteomyelitis may result from the elimination of the cells responsible for new bone matrix deposition in addition to the increased numbers and activity of bone resorbing osteoclasts at sites of bacterial infection (Nair et al., 1996). Along these lines, it is becoming apparent that the causative agents of osteomyelitis are capable of inducing continuous apoptosis of bone lining osteoblasts by activating intrinsic and extrinsic cell death pathways to further uncouple bone formation and resorption.

\section{DIRECT INDUCTION OF OSTEOBLAST CELL DEATH FOLLOWING BACTERIAL CHALLENGE}

Clinical S. aureus strain biofilm components have been shown to inhibit osteoblast differentiation and reduce viability with increased rates of apoptosis (Sanchez et al., 2013). Similarly, $S$. aureus binding to osteoblasts inhibits de novo bone formation by preventing expression of key products including alkaline phosphatase, collagen type I, osteocalcin, and osteopontin (Widaa et al., 2012). SpA appears to underlie this effect as this product can directly bind osteoblasts, inhibit proliferation and mineralization, and initiate apoptosis in this cell type (Claro et al., 2011). A role for SpA binding to osteoblasts in inducing apoptosis is supported by the observation that these effects are not seen with SpA deficient bacterial mutants (Claro et al., 2011; Widaa et al., 2012). Similarly, A. actinomycetemcomitans extracts can also induce the death of osteoblast-like cells (Morimoto et al., 1999). Again, a bacterial protein product appears to underlie this phenomenon as cycloheximide-treated A. actinomycetemcomitans fails to induce osteoblast death, and heat or trypsin treatment of bacterial extracts neutralizes this effect (Morimoto et al., 1999). Although, it should be noted that at least one study suggests that $A$. actinomycetemcomitans-induced osteoblast apoptosis can be mediated by a capsular-like polysaccharide (Yamamoto et al., 1999). Interestingly, while $P$. gingivalis lipids can inhibit osteoblast differentiation and activity, they do not significantly alter osteoblast viability (Wang et al., 2010), but binding between the fimbriae of this organism and the host cell integrin alpha5betal can initiate apoptosis in this cell type (Zhang et al., 2013). However, such induction appears to be a delayed effect as $P$. gingivalis prolongs cell life prior to host cell destruction (Zhang et al., 2013), presumably to permit bacterial replication within the osteoblast.

We have demonstrated that osteoblasts express members of the TLR family of pattern recognition receptors and that these cell surface sensors can detect the presence of extracellular bacteria and their products (Kikuchi et al., 2001; Gasper et al., 2002; Madrazo et al., 2003). However, our studies indicate that bacterial components, UV-inactivated bacteria and invasion defective strains of bacteria are far less effective in eliciting the osteoblast immune functions than viable wild type bacteria (Bost et al., 1999, 2000, 2001). Furthermore, Thammasitboon et al. (2006) have demonstrated that bacterial components such as LPS fail to elicit apoptosis in osteoblasts. Consistent with these findings, we have shown that cytochalasin significantly attenuates inflammatory cytokine production by invasive Salmonella (McCall et al., 2008). These observations indicate that invasion is required for optimal osteoblast responses and suggest that the cell surface TLRs are not the only means by which these cells perceive bacterial pathogens. This phenomenon might be explained by our finding that osteoblasts express NOD1 and NOD2 (Marriott et al., 2005), two members of the NLR family of receptor proteins that can serve as intracellular sensors for bacterial peptidoglycans and 
initiate pro-inflammatory mediator production (as reviewed in Ting and Davis, 2005; Strober et al., 2006).

The importance of bacterial invasion in the initiation of osteoblast apoptosis is underscored by the demonstration that the presence of intracellular $S$. aureus causes rounding of this cell type and chromatin condensation, DNA laddering, and DNA strand breaks in the nuclei (Tucker et al., 2000). Furthermore, S. aureus-induced apoptosis in human osteoblasts is markedly attenuated following inhibition of cellular invasion (Ning et al., 2011). Similarly, the Gram-negative bacteria $P$. gingivalis and B. abortus, causative agents of periodontitis and osteomyelitis, respectively, are capable of invading osteoblasts, although these organisms appear to elicit delayed apoptosis thereby permitting intracellular replication (Wang et al., 2010; Scian et al., 2012; Baldi and Giambartolomei, 2013; Zhang et al., 2013). Finally, similar to inflammatory mediator production, our studies indicate that invasive bacteria are more effective at inducing osteoblast apoptosis with S. aureus or S. typhimurium SB300 being significantly more potent stimuli for murine osteoblast cell death than the invasion defective species, S. carnosus and S. typhimurium SB136 (Marriott et al., 2005).

While NOD1 and NOD2 can initiate, augment, or reduce inflammatory mediator production by a variety of cell types (as reviewed in Inohara and Nunez, 2003), these cytosolic proteins are not widely recognized to participate in the induction of apoptosis. In contrast, two related receptors, NLR family CARD domain containing 4 (NLRC4) and NLR family pyrin domain containing 3 (NLRP3), have been implicated in the induction of cell death in response to bacteria and/or their components (Gumucio et al., 2002; Mariathasan et al., 2004, 2006; Sutterwala et al., 2006). Both of these molecules can associate with an adaptor protein, apoptosis-associated speck-like protein (ASC) to elicit caspase-1 and caspase-8 activation (Hasegawa et al., 2005; Mariathasan, 2007), enzymes that demonstrate elevated activity in osteoblasts following bacterial challenge (Marriott et al., 2002; Alexander et al., 2003). We have recently investigated the functional expression of NLRP3 and NLRC4 in resting and Salmonella exposed cultures of primary murine and human osteoblasts in an attempt to identify the mechanisms linking intracellular invasion to bacterially-induced cell death. We demonstrated that osteoblasts constitutively express NLRP3, but not NLRC4, and such expression was modestly increased following infection with wild type S. enterica (McCall et al., 2008). This finding was in contrast with the significant decrease in NLRP3 protein levels seen in osteoblasts following exposure to an invasion defective strain. In addition to showing that osteoblasts possess robust constitutive levels of NLRP3, we demonstrated that these cells also express ASC. While constitutive levels of ASC were low in resting osteoblasts, a marked elevation in expression was observed in cells following Salmonella infection (McCall et al., 2008).

Taken together, the conserved expression of NLRP3 and ASC in both mouse and human osteoblasts, and the sensitivity of such expression to bacterial challenge, provides circumstantial evidence of a role for these cytosolic proteins in osteoblast responses to intracellular pathogens. However, we have more directly verified NLRP3 functionality in bacterially challenged osteoblasts (McCall et al., 2008). First, we have shown that NLRP3 associates with ASC following exposure to Salmonella as determined by co-immunoprecipitation. Second, we have demonstrated that NLRP3 expression knockdown by siRNA attenuates Salmonellainduced changes in transcription factor activity. Third, we have found that osteoblasts derived from NLRP3 deficient animals produce less IL- 6 than cells derived from wild type mice. As such, these findings confirm that NLRP3 mediates, at least in part, osteoblast responses to this intracellular bacterial pathogen.

Given that osteoblasts constitutively express NLRP3 and ASC, and the finding that NLRP3 can associate with ASC to elicit caspase-1 (Gumucio et al., 2002; Dowds et al., 2004; Kanneganti et al., 2006; Mariathasan et al., 2006) and perhaps caspase8 activation (Hasegawa et al., 2005), enzymes that demonstrate elevated activity in osteoblasts following bacterial challenge (Marriott et al., 2002; Alexander et al., 2003), this cytosolic NLR may represent an important mechanism underlying osteoblast apoptosis following exposure to intracellular bacterial pathogens. This hypothesis is supported by our observation that Salmonellainduced decreases in NF-kB activity are markedly attenuated in osteoblasts following siRNA-induced NLRP3 knockdown (McCall et al., 2008), since this transcription factor has been reported to mediate anti-apoptotic effects in a variety of cell types (You et al., 2001; Lu et al., 2004; Munshi et al., 2004). Furthermore, we have shown that Salmonella-induced caspase-1 activation is absent in osteoblasts derived from NLRP3 deficient animals (McCall et al., 2008). More importantly, we have demonstrated that such cells exhibit significantly less apoptotic cell death following Salmonella infection than osteoblasts derived from wild type animals (McCall et al., 2008). These findings differ from studies in macrophages (Mariathasan et al., 2004, 2006) where NLRP3 is not required for Salmonella-induced caspase-1 activation, IL- $1 \beta$ production, or cell death. Instead, these functions are predominantly mediated by NLRC4 (Mariathasan et al., 2004, 2006). In osteoblasts, NLRP3 is required for caspase-1 activation and for a portion of Salmonella-induced cell death, while NLRC4 is not detectable in these cells. Furthermore, earlier work from our laboratory has indicated that neither the precursor nor the mature form of IL- $1 \beta$ is produced by infected osteoblasts (Marriott et al., 2002). Together these studies underscore the differences between osteoblasts and macrophages and show that at least one of these is a differential reliance on NLRP3 vs. NLRC4 in cell death following Salmonella infection. This illustrates an additional level of complexity in the control of cellular functions by NLR family members.

While further experimentation is required to definitively conclude that ASC and alterations in NF-kB activity are essential mechanistic elements in NLRP3-mediated apoptosis in bacterially challenged osteoblasts, these studies indicate that this NLR represents an important component underlying the direct initiation of apoptosis in this bone-forming cell type following challenge with intracellular bacterial pathogens and could, therefore, be a major contributory factor to bone loss at sites of infection.

\section{INDIRECT INDUCTION OF OSTEOBLAST CELL DEATH VIA LEUKOCYTE/BONE CELL DERIVED MEDIATORS}

The extrinsic pathway of programmed cell death begins with ligation of a particular group of cell surface receptors and leads to 
recruitment of adaptor molecules and the activation of a caspase cascade that results in cellular disassembly. This apoptotic pathway is critically regulated by members of the TNF family of cytokines and receptors in many cell types (Cosman, 1994; Lynch et al., 1994; Smith et al., 1994). Ligands such as TNF- $\alpha$ and Fas ligand have the ability to interact with death domain containing receptors to initiate apoptosis and conditioned medium from LPS-treated macrophage-like cells has been shown to induce osteoblast apoptosis in a TNF- $\alpha$ dependent manner (Thammasitboon et al., 2006). Similarly, the supernatants from $B$. abortus-infected macrophages can induce osteoblast apoptosis in a TNF- $\alpha$-dependent manner (Scian et al., 2012), which could therefore contribute to the bone and joint destruction seen in patients with osteoarticular complications of brucellosis. However, it is important to note that the events that occur in vivo are likely to be more complex as illustrated by the observation that LPS-induced TNF- $\alpha$ production only provokes in situ osteoblast apoptosis when the TNFR1 signal is negated, suggesting that this receptor can also regulate osteoblast survival (Ochi et al., 2010).

TNF-related apoptosis inducing ligand (TRAIL) is also a member of the TNF superfamily and this soluble protein has the unique ability to interact with five different receptors. TRAIL can interact with death receptor (DR) 4 (also known as TRAIL R1) (Pan et al., 1997), DR5 (also known as TRAIL R2 and TRAIL receptor inducer of cell killing-2) (Schneider et al., 1997), DcR1 (also known as TRAIL R3 and TRAIL receptor without an intracellular domain) (Degli-Esposti et al., 1997), DcR2 (also known as TRAIL R4 and TRAIL receptor with a truncated death-domain) (Pan et al., 1998), and finally soluble OPG (Emery et al., 1998). Of these receptors, only DR4 and DR5 in humans and DR5 in mice have functional cytoplasmic death-domains and are capable of inducing apoptosis, while DcR1 and DcR2 appear to function as decoy receptors (Clancy et al., 2005). Death domain-containing receptors trimerize to allow TRAIL to bind and trigger caspase 8 activation that directly activates caspases 3 and 7 via the extrinsic pathway (Clancy et al., 2005). Although it should be noted that that TRAIL has been also been suggested to activate the intrinsic pathway through the activation of $\mathrm{BH} 3$ interaction-domain death agonist (Bid) (Suliman et al., 2001; Sinicrope and Penington, 2005). Both of these pathways lead to caspase 3 activation and cell death (Suliman et al., 2001). In contrast, OPG appears to function as a soluble decoy receptor for both TRAIL and the potent osteoclastogenic factor, RANKL. As such, excessive TRAIL secretion in bone tissue would be anticipated to decrease the amount of OPG available to bind RANKL, leading to increased osteoclastogenesis and tissue loss (as illustrated in Figure 1).

In a recent study (Young et al., 2011), we have demonstrated that murine osteoblasts constitutively express mRNA encoding the sole murine death-domain containing TRAIL receptor, DR5, and we have shown that resting cultures of these cells contain robust levels of the DR5 protein. These observations are consistent with previous reports that human osteoblast-like cells express mRNA encoding DR4 and DR5 (Atkins et al., 2002). However, we have shown that DR5 expression on the surface of murine osteoblasts is restricted to cells exposed to either $S$. aureus or Salmonella (Young et al., 2011). Similarly, we confirmed that both of the death-domain containing TRAIL receptors on human cells are only present on primary human osteoblasts following bacterial challenge and the conserved nature of this response supports the biological significance of such expression on infected cells (Young et al., 2011). In the same work, we showed that the robust constitutive production of the decoy TRAIL receptor OPG by resting osteoblasts was markedly attenuated following infection with either S. aureus or Salmonella (Young et al., 2011). While other studies indicate that serum OPG levels increase following systemic bacterial LPS administration (Maruyama et al., 2006), our results are consistent with reports that the causative agents of periodontitis and LPS can similarly decrease OPG expression by murine osteoblasts (Chung et al., 2006; Mori et al., 2007). Furthermore, it should be noted that bone tissue is relatively poorly vascularized and bone infections are more commonly associated with Gram-positive bacterial species such as S. aureus, infections that do not result in the development of endotoxic shock. As such, changes in OPG expression by resident bone cells are likely to be more physiologically relevant in local bone infections than the systemic effects elicited by bacterial endotoxins. As such, these data suggest that the principle causative agents of osteomyelitis can elicit an imbalance in the expression of deathinducing and decoy TRAIL receptors by osteoblasts, with the induced expression of DR5 and/or DR4 on the surface of infected cells and a concomitant decrease in the production of the decoy receptor, OPG.

Osteoblasts isolated from alveolar bone of patients with periodontal disease have been demonstrated to have higher sensitivity to the apoptosis-inducing actions of TRAIL than cells isolated from healthy donors (Mori et al., 2009). In our recent work, we tested the sensitivity of primary osteoblasts to exogenously administered recombinant TRAIL at rest or following challenge with either S. aureus or Salmonella (Young et al., 2011). Consistent with the absence of death-inducing TRAIL receptors on uninfected osteoblasts and previous reports with unstimulated human osteoblast-like cells (Atkins et al., 2002; Bu et al., 2003), we showed that TRAIL fails to activate apoptosis signaling pathways in uninfected primary osteoblasts (Young et al., 2011). However, acute bacterial exposure sensitizes osteoblasts to TRAIL-mediated cell death as shown by the ability of exogenous TRAIL to augment apoptotic volume decreases and caspase- 8 activation following S. aureus or Salmonella infection (Alexander et al., 2003; Young et al., 2011). While increased TRAIL-induced apoptosis is only correlative with the observed induction of cell surface death receptor expression, we have previously documented that TRAIL neutralizing antibodies can significantly inhibit bacterially-induced osteoblast apoptosis as assessed by caspase- 8 activation and annexin $\mathrm{V}$ staining (Alexander et al., 2003). Together, these results support the contention that the induced expression of death receptors renders these cells sensitive to the apoptotic actions of TRAIL, and provide a potential mechanism underlying the reported increase in TRAIL sensitivity of human alveolar osteoblasts isolated from patients with periodontitis (Mori et al., 2009) and transformed osteoblasts (Atkins et al., 2002).

Several studies have shown that human osteoblast-like cells express TRAIL (Atkins et al., 2002; Bu et al., 2003) and work from our laboratory has demonstrated that exposure of mouse 
and human primary osteoblasts to S. aureus or Salmonella induces TRAIL expression by these cells (Alexander et al., 2001). Furthermore, we have also shown that bacterial infection enhances RANKL expression and release by osteoblasts (Somayaji et al., 2008). Since RANKL binds OPG with a similar binding affinity to that of TRAIL (23 and $45 \mathrm{nM}$ for RANKL and TRAIL, respectively (Vitovski et al., 2007), this molecule could further reduce levels of OPG available to bind and neutralize TRAIL. Accordingly, a scenario could be envisaged in which bacterially challenged osteoblasts express TRAIL and RANKL while concomitantly decreasing the production of the decoy receptor OPG and upregulating cell surface death receptor expression. The increased production of this death receptor ligand, in concert with reduced OPG production and bioavailability, would facilitate TRAIL activity and result in the death of infected osteoblasts, providing an additional mechanism whereby bacterial pathogens elicit bone destruction during diseases such as osteomyelitis (as shown in Figure 1).

\section{CONCLUDING REMARKS}

The inflammatory bone loss associated with osteomyelitis can result from the direct destruction of bone tissue by bacteria and their products. Furthermore, significant bone loss is likely to result from the recruitment and activation of infiltrating leukocytes such as neutrophils and macrophages. The direct activation of these cells by bacteria via an array of cell surface and cytosolic pattern recognition receptors, and the presence of an inflammatory milieu at the site of infection, results in the production of degradative enzymes and cytotoxic molecules. Consistent with host-pathogen interactions at other anatomical sites, the microbes responsible for bone infections can manipulate leukocyte survival pathways in a bacterium specific manner with some organisms inducing apoptosis and/or pyroptotic cell death, while other organisms appear to promote the survival of innate immune cells, particularly neutrophils. While lengthening the life span of these cells might represent an attempt by the host to clear the infection, the unintended consequence of such a vigorous response can be extensive inflammatory bone destruction.

However, bone loss at sites of infection is primarily due to an uncoupling of the control of bone forming osteoblasts and bone resorbing osteoclasts. Bacteria or their products can directly increase the osteoclast formation and activity. In addition, inflammatory mediators produced at the site by infiltrating leukocytes or bacterially challenged osteoclasts themselves can further promote osteoclastogenesis and bone resorption. Importantly, the production and activity of osteoclasts is critically regulated by osteoblasts, and these cells have recently been found to respond to the principle causative agents of osteomyelitis via TLR and NLR family members. Osteoblasts exposed to bacteria express an array of soluble and cell surface molecules that have the potential to promote immune responses and directly or indirectly enhance osteoclast activity at sites of infection.

In addition to the increased number and activity of bone resorbing osteoclasts, it is becoming apparent that bone loss during conditions such as osteomyelitis is also brought about by a decline in new bone deposition. This occurs as a result of decreased production of matrix components by osteoblasts and by increased rates of apoptosis in this cell type. While the presence of certain extracellular bacterial components may be sufficient to directly reduce osteoblast viability, there is considerable evidence that internalization of the principal causative agents of osteomyelitis is required to maximally induce apoptosis in these cells. At least a component of such cell death is attributable to osteoblast-derived TRAIL acting in an autocrine and/or paracrine manner via death domain-containing receptors that are concomitantly and exclusively expressed by infected cells. However, TRAIL-induced death is unlikely to be the sole means by which osteoblasts are eliminated in infected tissue. Indeed, rapid activation of apoptotic pathways is observed in microbe challenged osteoblasts prior to TRAIL production, and at least a proportion of this cell death is unaffected by anti-TRAIL antibodies (Alexander et al., 2001, 2003). Such cell death may result from the direct activation of cytosolic NLRP3 that is constitutively expressed by osteoblasts (McCall et al., 2008), which can activate caspase cascades and initiate apoptosis. As such, NLRP3 may act in concert with TRAIL-mediated pathways to eliminate osteoblasts in infected bone tissue.

It might be anticipated that new therapies that target the perception and initiation of inflammatory immune responses and bone-forming cell death via pattern recognition receptors would be of considerable benefit in reducing the inflammatory damage and cell death associated with bone infections. However, it is important to note that many of these observations have been made in reductive in vitro systems and have yet to be confirmed in vivo. Also, it is clear that important issues regarding bacteriainduced inflammatory bone loss remain unresolved. For example, it is not known whether osteocytes embedded within calcified bone can respond to bacteria, an important question given the critical role of cell type in controlling bone surface cells via the lacuna-canaliculi network (Matsuo, 2009). Furthermore, the mechanism that is the most important in the pathophysiology of bacterium-induced bone loss has not been identified, and this issue is further complicated by the disparate nature of the bacterial species that are responsible for bone diseases. As such, it is not presently known whether inhibition of osteoclast formation/activity or the prevention of osteoblast destruction would be most efficient in eliminating bacterially-induced bone loss. Finally, given that infected osteoblasts may harbor intracellular bacteria such as $S$. aureus and promote inflammatory bone damage, it is not clear whether the host would be best served by preventing osteoblast cell death or by eliminating these cells via the induction of apoptosis. Clearly, further work is warranted to resolve these issues.

\section{REFERENCES}

Ahmed, S., Meghji, S., Williams, R. J., Henderson, B., Brock, J. H., and Nair, S. P. (2001). Staphylococcus aureus fibronectin binding proteins are essential for internalization by osteoblasts but do not account for differences in intracellular levels of bacteria. Infect. Immun. 69, 2872-2877. doi: 10.1128/IAI.69.5.28722877.2001

Alexander, E. H., Rivera, F. A., Marriott, I., Anguita, J., Bost, K. L., and Hudson, M. C. (2003). Staphylococcus aureus-induced tumor necrosis factor-related apoptosis-inducing ligand expression mediates apoptosis and caspase- 8 activation in infected osteoblasts. BMC Microbiol. 3:5. doi: 10.1186/1471-2180-3-5

Alexander, E. H., Bento, J. L., Hughes, F. M. Jr., Marriott, I., Hudson, M. C., and Bost, K. L. (2001). Staphylococcus aureus and Salmonella enterica serovar 
Dublin induce tumor necrosis factor-related apoptosis-inducing ligand expression by normal mouse and human osteoblasts, Infect. Immun. 69, 1581-1586. doi: 10.1128/IAI.69.3.1581-1586.2001

Anand, A. J., and Glatt, A. E. (1994). Salmonella osteomyelitis and arthritis in sickle cell disease. Semin. Arthritis Rheum. 24, 211-221. doi: 10.1016/00490172(94)90076-0

Anderson, D. M., Maraskovsky, E., Billingsley, W. L., Dougall, W. C., Tometsko, M. E., Roux, E. R., et al. (1997). A homologue of the TNF receptor and its ligand enhance T-cell growth and dendritic-cell function. Nature 390, 175-179. doi: $10.1038 / 36593$

Arnold, S. R., Elias, D., Buckingham, S. C., Thomas, E. D., Novais, E., Arkader, A., et al. (2006). Changing patterns of acute hematogenous osteomyelitis and septic arthritis: emergence of community-associated methicillin-resistant Staphylococcus aureus. J. Pediatr. Orthop. 26, 703-708. doi: 10.1097/01.bpo. 0000242431.91489.b4

Asensi, V., Valle, E., Meana, A., Fierer, J., Celada, A., Alvarez, V., et al. (2004). In vivo interleukin-6 protects neutrophils from apoptosis in osteomyelitis. Infect. Immun. 72, 3823-3828. doi: 10.1128/IAI.72.7.3823-3828.2004

Atkins, G. J., Bouralexis, S., Evdokiou, A., Hay, S., Labrinidis, A., Zannettino, A. C., et al. (2002). Human osteoblasts are resistant to Apo2L/TRAIL-mediated apoptosis. Bone 31, 448-456. doi: 10.1016/S8756-3282(02)00858-X

Baldi, P. C., and Giambartolomei, G. H. (2013). Pathogenesis and pathobiology of zoonotic brucellosis in humans. Rev. Sci. Tech. 32, 117-125.

Barton, G. M., and Medzhitov, R. (2003). Toll-like receptor signaling pathways. Science 300, 1524-1525. doi: 10.1126/science. 1085536

Barton, L. L., Dunkle, L. M., and Habib, F. H. (1987). Septic arthritis in childhood. A 13-year review. Am. J. Dis. Child. 141, 898-900. doi: 10.1001/archpedi.1987.04460080084034

Boneca, I. G., and Chiosis, G. (2003). Vancomycin resistance: occurrence, mechanisms and strategies to combat it. Expert Opin. Ther. Targets 7, 311-328. doi: 10.1517/14728222.7.3.311

Bost, K. L., Bento, J. L., Ellington, J. K., Marriott, I., and Hudson, M. C. (2000). Induction of colony-stimulating factor expression following Staphylococcus or Salmonella interaction with mouse or human osteoblasts. Infect. Immun. 68, 5075-5083. doi: 10.1128/IAI.68.9.5075-5083.2000

Bost, K. L., Bento, J. L., Petty, C. C., Schrum, L. W., Hudson, M. C., and Marriott, I. (2001). Monocyte chemoattractant protein-1 expression by osteoblasts following infection with Staphylococcus aureus or Salmonella. J. Interf. Cytok Res. 21, 297-304. doi: 10.1089/107999001300177484

Bost, K. L., Ramp, W. K., Nicholson, N., Bento, J. L., Marriott, I., and Hudson, M. C. (1999). Staphylococcus aureus infection of mouse or human osteoblasts induces high levels of IL-6 and IL-12 production. J. Infect. Dis. 180, 1912-1920. doi: $10.1086 / 315138$

Brady, R. A., Leid, J. G., Calhoun, J. H., Costerton, J. W., and Shirtliff, M. E. (2008). Osteomyelitis and the role of biofilms in chronic infection. FEMS Immunol. Med. Microbiol. 52, 13-22. doi: 10.1111/j.1574-695X.2007.00357.x

Bremell, T., Lange, S., Holmdahl, R., Ryden, C., Hansson, G. K., and Tarkowski A. (1994). Immunopathological features of rat Staphylococcus aureus arthritis. Infect. Immun. 62, 2334-2344.

Bu, R., Borysenko, C. W., Li, Y., Cao, L., Sabokbar, A., and Blair, H. C. (2003). Expression and function of TNF-family proteins and receptors in human osteoblasts. Bone 33, 760-770. doi: 10.1016/S8756-3282(03)00271-0

Cha, S. B., Lee, W. J., Shin, M. K., Jung, M. H., Shin, S. W., Yoo, A. N., et al. (2013). Early transcriptional responses of internalization defective Brucella abortus mutants in professional phagocytes, RAW 264.7. BMC Genomics 14:426. doi: 10.1186/1471-2164-14-426

Chauhan, V. S., and Marriott, I. (2010). Differential roles for NOD2 in osteoblast inflammatory immune responses to bacterial pathogens of bone tissue. J. Med. Microbiol. 59, 755-762. doi: 10.1099/jmm.0.015859-0

Choi, B. K., Moon, S. Y., Cha, J. H., Kim, K. W., and Yoo, Y. J. (2005). Prostaglandin E(2) is a main mediator in receptor activator of nuclear factorkappaB ligand-dependent osteoclastogenesis induced by Porphyromonas gingivalis, Treponema denticola, and Treponema socranskii. J. Periodontol. 76, 813-820. doi: 10.1902/jop.2005.76.5.813

Chung, Y. H., Chang, E. J., Kim, S. J., Kim, H. H., Kim, H. M., Lee, S. B., et al. (2006). Lipopolysaccharide from Prevotella nigrescens stimulates osteoclastogenesis in cocultures of bone marrow mononuclear cells and primary osteoblasts. J. Periodont. Res. 41, 288-296. doi: 10.1111/j.1600-0765.2006.00876.x
Clancy, L., Mruk, K., Archer, K., Woelfel, M., Mongkolsapaya, J., Screaton, G., et al. (2005). Preligand assembly domain-mediated ligand-independent association between TRAIL receptor 4 (TR4) and TR2 regulates TRAIL-induced apoptosis. Proc. Natl. Acad. Sci. U.S.A. 102, 18099-180104. doi: 10.1073/pnas.0507329102

Claro, T., Widaa, A., McDonnell, C., Foster, T. J., O'Brien, F. J., and Kerrigan, S. W. (2013). Staphylococcus aureus protein A binding to osteoblast tumour necrosis factor receptor 1 results in activation of nuclear factor kappa B and release of interleukin-6 in bone infection. Microbiology 159, 147-154. doi: 10.1099/mic.0. 063016-0

Claro, T., Widaa, A., O’Seaghdha, M., Miajlovic, H., Foster, T. J., O’Brien, F. J., et al. (2011). Staphylococcus aureus protein A binds to osteoblasts and triggers signals that weaken bone in osteomyelitis. PLoS ONE 6:e18748. doi: 10.1371/journal.pone.0018748

Cosman, D. (1994). A family of ligands for the TNF receptor superfamily. Stem Cells. 12, 440-455. doi: 10.1002/stem.5530120501

Dale, D. C. (1995). Where now for colony-stimulating factors? Lancet 346, 135-136. doi: 10.1016/S0140-6736(95)91206-1

Davis, J. S. (2005). Management of bone and joint infections due to Staphylococcus aureus. Intern. Med. J. 35, S79-S96. doi: 10.1111/j.1444-0903.2005.00982.x

De Boeck, H. (2005). Osteomyelitis and septic arthritis in children. Acta Orthop. Belg. 71, 505-515.

Degli-Esposti, M. A., Smolak, P. J., Walczak, H., Waugh, J., Huang, C. P., DuBose, R. F., et al. (1997). Cloning and characterization of TRAIL-R3, a novel member of the emerging TRAIL receptor family. J. Exp. Med. 186, 1165-1170. doi: 10.1084/ jem.186.7.1165

de la Mata, J., Uy, H. L., Guise, T. A., Story, B., Boyce, B. F., Mundy, G. R., et al. (1995). Interleukin-6 enhances hypercalcemia and bone resorption mediated by parathyroid hormone-related protein in vivo. J. Clin. Invest. 95, 2846-2852. doi: $10.1172 /$ JCI117990

Dowds, T. A., Masumoto, J., Zhu, L., Inohara, N., and Nunez, G. (2004). Cryopyrininduced interleukin lbeta secretion in monocytic cells: enhanced activity of disease-associated mutants and requirement for, ASC. J. Biol. Chem. 279, 21924-21928. doi: 10.1074/jbc.M401178200

Dubey, L., Krasinski, K., and Hernanz-Schulman, M. (1988). Osteomyelitis secondary to trauma or infected contiguous soft tissue. Pediatr Infect Dis, J. 7, 26-34. doi: 10.1097/00006454-198801000-00007

Ellington, J. K., Harris, M., Hudson, M. C., Vishin, S., Webb, L. X., and Sherertz, R. (2006). Intracellular Staphylococcus aureus and antibiotic resistance: implications for treatment of staphylococcal osteomyelitis. J. Orthop. Res. 24, 87-93. doi: 10.1002/jor.20003

Ellington, J. K., Harris, M., Webb, L., Smith, B., Smith, T. and, Tan, K., et al. (2003). Intracellular Staphylococcus aureus. A mechanism for the indolence of osteomyelitis. J. Bone Joint Surg. Br. 85, 918-921. doi: 10.1302/0301-620X.85B6. 13509

Ellington, J. K., Reilly, S. S., Ramp, W. K., Smeltzer, M. S., Kellam, J. F., and Hudson, M. C. (1999). Mechanisms of Staphylococcus aureus invasion of cultured osteoblasts. Microb. Pathog. 26, 317-323. doi: 10.1006/mpat. 1999.0272

Emery, J. G., McDonnell, P., Burke, M. B., Deen, K. C., Lyn, S., Silverman, C., et al. (1998). Osteoprotegerin is a receptor for the cytotoxic ligand, TRAIL. J. Biol. Chem. 273, 14363-14367. doi: 10.1074/jbc.273.23.14363

Fink, S. L., and Cookson, B. T. (2007). Pyroptosis and host cell death responses during Salmonella infection. Cell. Microbiol. 9, 2562-2570. doi: 10.1111/j.14625822.2007.01036.x

Frenck, R. W., Sarman, G., Harper, T. E., and Buescher, E. S. (1990). The ability of recombinant murine granulocyte-macrophage colony-stimulating factor to protect neonatal rats from septic death due to Staphylococcus aureus. J. Infect. Dis. 162, 109-114. doi: 10.1093/infdis/162.1.109

Freund, M., and Kleine, H. D. (1992). The role of GM-CSF in infection. Infection 20:S84-S92. doi: 10.1007/BF01705024

Friedrich, N., Hagedorn M., Soldati-Favre D., and Soldati, T. (2012). Prison break: pathogens' strategies to egress from host cells. Microbiol. Mol. Biol. Rev. 76, 707-720. doi: 10.1128/MMBR.00024-12

Fujimura, Y., Hotokezaka, H., Ohara, N., Naito, M., Sakai, E., Yoshimura, M., et al. (2006). The hemoglobin receptor protein of porphyromonas gingivalis inhibits receptor activator NF-kappaB ligand-induced osteoclastogenesis from bone marrow macrophages. Infect. Immun. 74, 2544-2551. doi: 10.1128/IAI. 74.5.2544-2551.2006 
Gasper, N. A., Petty, C. C., Schrum, L. W., Marriott, I., and Bost, K. L. (2002). Bacterium-induced CXCL10 secretion by osteoblasts can be mediated in part through Toll-Like Receptor 4. Infect. Immun. 70, 4075-4082. doi: 10.1128/ IAI.70.8.4075-4082.2002

Greenfield, E. M., Shaw, S. M., Gornik, S. A., and Banks, M. A. (1995). Adenyl cyclase and interleukin 6 are downstream effectors of parathyroid hormone resulting in stimulation of bone resorption. J. Clin. Invest. 96, 1238-1244. doi: 10.1172/JCI118157

Gumucio, D. L., Diaz, A., Schaner, P., Richards, N., Babcock, C., Schaller, M., et al. (2002). Fire and ICE: the role of pyrin domain-containing proteins in inflammation and apoptosis. Clin. Exp. Rheumatol. 20, S45-S53.

Hanke, M. L., and Kielian, T. (2012). Deciphering mechanisms of staphylococcal biofilm evasion of host immunity. Front. Cell Infect. Microbiol. 2:62. doi: 10.3389/fcimb.2012.00062

Hasegawa, M., Imamura, R., Kinoshita, T., Matsumoto, N., Masumoto, J., Inohara, N., et al. (2005). ASC-mediated NF-kappaB activation leading to interleukin-8 production requires caspase- 8 and is inhibited by, CLARP. J. Biol. Chem. 280, 15122-15130. doi: 10.1074/jbc.M412284200

Heseltine, P. (2000). Has resistance spread to the community? Clin. Microbiol. Infect. 6, 11-16. doi: 10.1046/j.1469-0691.2000.00004.x

Hofbauer, L. C., and Heufelder, A. E. (1996). Intercellular chatter: osteoblasts, osteoclasts and interleukin 6. Eur. J. Endocrinol. 134, 425-426. doi: 10.1530/eje.0.1340425

Horwood, N. J., Kartsogiannis, V., Quinn, J. M., Romas, E., Martin, T. J., and Gillespie, M. T. (1999). Activated T lymphocytes support osteoclast formation in vitro. Biochem. Biophys. Res. Commun. 265, 144-150. doi: 10.1006/bbrc. 1999.1623

Hsu, H., Lacey, D. L., Dunstan, C. R., Solovyev, I., Colombero, A., Timms, E., et al. (1999). Tumor necrosis factor receptor family member RANK mediates osteoclast differentiation and activation induced by osteoprotegerin ligand. Proc. Natl. Acad. Sci. U.S.A. 96, 3540-3545. doi: 10.1073/pnas.96.7.3540

Hudson, M. C., Ramp, W. K., Nicholson, N. C., Williams, A. S., and Nousiainen, M. T. (1995). Internalization of Staphylococcus aureus by cultured osteoblasts. Microb. Pathog. 19, 409-419. doi: 10.1006/mpat.1995.0075

Inohara, N., and Nunez, G. (2003). NODs: intracellular proteins involved in inflammation and apoptosis. Nat. Rev. Immunol. 3, 371-382. doi: 10.1038/nri1086

Ishimi, Y., Miyaura, C., Jin, C. H., Akatsu, T., Abe, E., Nakamura, Y., et al. (1990). IL-6 is produced by osteoblasts and induces bone resorption. J. Immunol. 145, 3297-3303.

Jensen, A. G., Espersen, F., Skinhoj, P., Rosdahl, V. T., and Frimodt-Moller, N. (1997). Increasing frequency of vertebral osteomyelitis following Staphylococcus aureus bacteraemia in Denmark 1980-1990. J. Infect. 34, 113-118. doi: 10.1016/S0163-4453(97)92395-1

Jensen, H. E., Nielsen, O. L., Agerholm, J. S., Iburg, T., Johansen, L. K., Johannesson, E., et al. (2010). A non-traumatic Staphylococcus aureus osteomyelitis model in pigs. In Vivo 24, 257-264.

Jevon, M., Guo, C., Ma, B., Mordan, N., Nair, S. P., Harris, M., et al. (1999). Mechanisms of internalization of Staphylococcus aureus by cultured human osteoblasts. Infect. Immun. 67, 2677-2681.

Jones, B. D., and Falkow, S. (1996). Salmonellosis: host immune responses and bacterial virulence determinants. Annu. Rev. Immunol. 14, 533-561. doi: 10.1146/annurev.immunol.14.1.533

Kanneganti, T. D., Body-Malapel, M., Amer, A., Park, J. H., Whitfield, J., Franchi, L., et al. (2006). Critical role for Cryopyrin/Nalp3 in activation of caspase-1 in response to viral infection and double-stranded, RNA. J. Biol. Chem. 281, 36560-36568. doi: 10.1074/jbc.M607594200

Kikuchi, T., Matsuguchi, T., Tsuboi, N., Mitani, A., Tanaka, S., Matsuoka, M., et al. (2001). Gene expression of osteoclast differentiation factor is induced by lipopolysaccharide in mouse osteoblasts via Toll-like receptors. J. Immunol. 166, 3574-3579.

Kim, N., Odgren, P. R., Kim, D. K., Marks, S. C. Jr., and Choi, Y. (2000). Diverse roles of the tumor necrosis factor family member TRANCE in skeletal physiology revealed by TRANCE deficiency and partial rescue by a lymphocyteexpressed TRANCE transgene. Proc. Natl. Acad. Sci. U.S.A. 97, 10905-10910. doi: 10.1073/pnas.200294797

Kodama, H., Nose, M., Niida, S., and Yamasaki, A. (1991). Essential role of macrophage colony-stimulating factor in the osteoclast differentiation supported by stromal cells. J. Exp. Med. 173, 1291-1294. doi: 10.1084/jem.173. 5.1291
Koehler, L., Zeidler, H., and Hudson, A. P. (1998). Aetiological agents: their molecular biology and phagocyte-host interaction. Baillieres Clin. Rheumatol. 12, 589-609. doi: 10.1016/S0950-3579(98)80039-3

Kong, Y. Y., Feige, U., Sarosi, I., Bolon, B., Tafuri, A., Morony, S., et al. (1999a). Activated $\mathrm{T}$ cells regulate bone loss and joint destruction in adjuvant arthritis through osteoprotegerin ligand. Nature 402, 304-309. doi: 10.1038/46303

Kong, Y. Y., Yoshida, H., Sarosi, I., Tan, H. L., Timms, E., Capparelli, C., et al. (1999b). OPGL is a key regulator of osteoclastogenesis, lymphocyte development and lymph-node organogenesis. Nature 397, 315-323. doi: 10.1038/16852

Labbé, J. L., Peres, O., Leclair, O., Goulon, R., Scemama, P., Jourdel, F., et al. (2010). Acute osteomyelitis in children: the pathogenesis revisited? Orthop. Traumatol. Surg. Res. 96, 268-275. doi: 10.1016/j.otsr.2009.12.012

Lau, Y. S., Wang, W., Sabokbar, A., Simpson, H., Nair, S., Henderson, B., et al. (2006). Staphylococcus aureus capsular material promotes osteoclast formation. Injury 37:S41-S48. doi: 10.1016/j.injury.2006.04.008

Lesclous, P., Abi Najm, S., Carrel, J. P., Baroukh, B., Lombardi, T., Willi, J. P., et al. (2009). Bisphosphonate-associated osteonecrosis of the jaw: a key role of inflammation? Bone. 45, 843-852. doi: 10.1016/j.bone.2009.07.011

Lew, D. P., and Waldvogel, F. A. (2004). Osteomyelitis. Lancet. 364, 369-379. doi: 10.1016/S0140-6736(04)16727-5

Li, J., Sarosi, I., Yan, X. Q., Morony, S., Capparelli, C., Tan, H. L., et al. (2000). RANK is the intrinsic hematopoietic cell surface receptor that controls osteoclastogenesis and regulation of bone mass and calcium metabolism. Proc. Natl. Acad. Sci. U.S.A. 97, 1566-1571. doi: 10.1073/pnas.97.4.1566

Liggett, W. Jr., Shevde, N., Anklesaria, P., Sohoni, S., Greenberger, J., and Glowacki, J. (1993). Effects of macrophage colony stimulating factor and granulocyte-macrophage colony stimulating factor on osteoclastic differentiation of hematopoietic progenitor cells. Stem Cells. 11, 398-411. doi: 10.1002/stem. 5530110507

Lorenzo, J. A., Sousa, S. L., Fonseca, J. M., Hock, J. M., and Medlock, E. S. (1987), Colony-stimulating factors regulate the development of multinucleated osteoclasts from recently replicated cells in vitro. J. Clin. Invest. 80, 160-164. doi: 10.1172/JCI113042

Lowik, C. W., van der Pluijm, G., Bloys, H., Hoekman, K., Bijvoet, O. L., Aarden, L. A., et al. (1989). Parathyroid hormone (PTH) and PTH-like protein (PLP) stimulate interleukin- 6 production by osteogenic cells: a possible role of interleukin6 in osteoclastogenesis. Biochem. Biophys. Res. Commun. 162, 1546-1552. doi: 10.1016/0006-291X(89)90851-6

Lu, T., Burdelya, L. G., Swiatkowski, S. M., Boiko, A. D., Howe, P. H., Stark, G. R., et al. (2004). Secreted transforming growth factor beta2 activates NF-kappaB, blocks apoptosis, and is essential for the survival of some tumor cells. Proc. Natl. Acad. Sci. U.S.A. 101, 7112-7117. doi: 10.1073/pnas.0402048101

Lynch, D. H., Watson, M. L., Alderson, M. R., Baum, P. R., Miller, R. E., Tough, T., et al. (1994). The mouse Fas-ligand gene is mutated in gld mice and is part of a TNF family gene cluster. Immunity 1, 131-136. doi: 10.1016/10747613(94)90106-6

Madeira, M. F., Queiroz-Junior, C. M., Cisalpino, D., Werneck, S. M., Kikuchi, H., Fujise, O., et al. (2013). MyD88 is essential for alveolar bone loss induced by Aggregatibacter actinomycetemcomitans lipopolysaccharide in mice. Mol. Oral Microbiol. 28, 415-424. doi: 10.1111/omi.12034

Madrazo, D. R., Tranguch, S. L., and Marriott, I. (2003). Signaling via Toll-like receptor 5 can initiate inflammatory mediator production by murine osteoblasts. Infect. Immun. 71, 5418-5421. doi: 10.1128/IAI.71.9.54185421.2003

Mariathasan, S. (2007). ASC, Ipaf and Cryopyrin/Nalp3: bona fide intracellular adapters of the caspase-1 inflammasome. Microbes Infect. 9, 664-671. doi: 10.1016/j.micinf.2007.01.017

Mariathasan, S., Newton, K., Monack, D. M., Vucic, D., French, D. M., Lee, W. P., et al. (2004). Differential activation of the inflammasome by caspase-1 adaptors ASC and Ipaf. Nature 430, 213-218. doi: 10.1038/nature02664

Mariathasan, S., Weiss, D. S., Newton, K., McBride, J., O’Rourke, K., Roose-Girma, M., et al. (2006). Cryopyrin activates the inflammasome in response to toxins and, ATP. Nature 440, 228-232. doi: 10.1038/nature04515

Marriott, I. (2004). Osteoblast responses to bacterial pathogens: a previously unappreciated role for bone-forming cells in host immune responses and disease progression. Immunol. Res. 30, 291-308. doi: 10.1385/IR:30:3:291

Marriott, I., Hughes, F. M. Jr., and Bost, K. L. (2002). Bacterial infection of osteoblasts induces interleukin-1beta and interleukin-18 transcription but not protein synthesis. J. Interferon Cytokine Res. 22, 1049-1055. doi: $10.1089 / 107999002760624288$ 
Marriott, I., Rati, D. M., McCall, S. H., and Tranguch, S. L. (2005). Induction of Nod1 and Nod2 intracellular pattern recognition receptors in murine osteoblasts following bacterial challenge. Infect. Immun. 73, 2967-2973. doi: 10.1128/IAI.73.5.2967-2973.2005

Maruyama, K., Takada, Y., Ray, N., Kishimoto, Y., Penninger, J. M., Yasuda, H., et al. (2006). Receptor activator of NF-kappa B ligand and osteoprotegerin regulate proinflammatory cytokine production in mice. J. Immunol. 177, 3799-3805.

Matsuo, K. (2009), Cross-talk among bone cells. Curr. Opin. Nephrol. Hypertens. 18, 292-297. doi: 10.1097/MNH.0b013e32832b75f1

McCall, S. H., Sahraei, M., Young, A. B., Worley, C. S., Duncan, J. A., Ting, J. P., et al. (2008). Osteoblasts express NLRP3, a nucleotide-binding domain and leucine-rich repeat region containing receptor implicated in bacterially induced cell death. J. Bone Miner. Res. 23, 30-40. doi: 10.1359/jbmr.071002

Meghji, S., Crean, S. J., Hill, P. A., Sheikh, M., Nair, S. P., Heron, K., et al. (1998). Surface-associated protein from Staphylococcus aureus stimulates osteoclastogenesis: possible role in, S. aureus-induced bone pathology. Br. J. Rheumatol. 37, 1095-1101. doi: 10.1093/rheumatology/37.10.1095

Meyle, E., Stroh, P., Günther, F., Hoppy-Tichy, T., Wagner, C., and Hänsch, G. M. (2010). Destruction of bacterial biofilms by polymorphonuclear neutrophils: relative contribution of phagocytosis, DNA release, and degranulation. Int. J. Artif. Organs 33, 608-620.

Montes, A. H., Asensi, V., Alvarez, V., Valle, E., Ocaña, M. G., Meana, A., et al. (2006). The Toll-like receptor 4 (Asp299Gly) polymorphism is a risk factor for Gram-negative and haematogenous osteomyelitis. Clin. Exp. Immunol. 143, 404-413. doi: 10.1111/j.1365-2249.2005.03002.x

Montonen, M., Li, T. F., Lukinmaa, P. L., Sakai, E., Hukkanen, M., Sukura, A., et al. (2006). RANKL and cathepsin $\mathrm{K}$ in diffuse sclerosing osteomyelitis of the mandible. J. Oral Pathol. Med. 35, 620-625. doi: 10.1111/j.16000714.2006.00454.x

Monzón, M., García-Alvarez, F., Laclériga, A., Gracia, E., Leiva, J., Oteiza, C., et al. (2001). A simple infection model using pre-colonized implants to reproduce rat chronic Staphylococcus aureus osteomyelitis and study antibiotic treatment. J. Orthop. Res. 19, 820-826. doi: 10.1016/S0736-0266(00)00 076-0

Mori, G., Brunetti, G., Colucci, S., Ciccolella, F., Coricciati, M., Pignataro, P., et al. (2007). Alteration of activity and survival of osteoblasts obtained from human periodontitis patients: role of, TRAIL. J. Biol. Regul. Homeost. Agents 21, 105-114.

Mori, G., Brunetti, G., Colucci, S., Oranger, A., Ciccolella, F., Sardone, F., et al. (2009). Osteoblast apoptosis in periodontal disease: role of TNF-related apoptosis-inducing ligand. Int. J. Immunopathol. Pharmacol. 22, 95-103.

Morimoto, Y., Morimoto, H., Murata, T., Kobayashi, S., Ohba, T., and Haneji, T. (1999). Extracts of Actinobacillus actinomycetemcomitans induce apoptotic cell death in human osteoblastic MG63 cells. J. Dent. Res. 78, 735-742. doi: 10.1177/00220345990780030501

Mousa, H. A. (2003). Bone infection. East. Mediterr. Health J. 9, 208-214.

Munshi, A., Kurland, J. F., Nishikawa, T., Chiao, P. J., Andreeff, M., and Meyn, R. E. (2004). Inhibition of constitutively activated nuclear factor-kappaB radiosensitizes human melanoma cells. Mol. Cancer Ther. 3, 985-992.

Nair, S. P., Meghji, S., Wilson, M., Reddi, K., White, P., and Henderson, B. (1996). Bacterially induced bone destruction: mechanisms and misconceptions. Infect. Immun. 64, 2371-2380.

Nair, S., Song, Y., Meghji, S., Reddi, K., Harris, M., Ross, A., et al. (1995). Surfaceassociated proteins from Staphylococcus aureus demonstrate potent bone resorbing activity. J. Bone Miner. Res. 10, 726-734. doi: 10.1002/jbmr.5650100509

Ning, R. D., Zhang, X. L., Li, Q. T., and Guo, X. K. (2011). The effect of Staphylococcus aureus on apoptosis of cultured human osteoblasts. Orthop. Surg. 3, 199-204. doi: 10.1111/j.1757-7861.2011.00146.x

Ocaña, M. G., Asensi, V., Montes, A. H., Meana, A., Celada, A., and Valle-Garay, E. (2008). Autoregulation mechanism of human neutrophil apoptosis during bacterial infection. Mol. Immunol. 45, 2087-2096. doi: 10.1016/j.molimm.2007. 10.013

Ocaña, M. G., Valle-Garay, E., Montes, A. H., Meana, A., Cartón, J. A., Fierer, J., et al. (2007). Bax gene G(-248)A promoter polymorphism is associated with increased lifespan of the neutrophils of patients with osteomyelitis. Genet. Med. 9, 249-255. doi: 10.1097/GIM.0b013e318039b23d

Ochi, H., Hara, Y., Tagawa, M., Shinomiya, K., and Asou, Y. (2010). The roles of TNFR1 in lipopolysaccharide-induced bone loss: dual effects of TNFR1 on bone metabolism via osteoclastogenesis and osteoblast survival. J. Orthop. Res. 28, 657-663. doi: 10.1002/jor.21028

Ohl, M. E., and Miller, S. I. (2001). Salmonella: a model for bacterial pathogenesis. Annu. Rev. Med. 52, 259-274. doi: 10.1146/annurev.med.52.1.259

Okahashi, N., Inaba, H., Nakagawa, I., Yamamura, T., Kuboniwa, M., Nakayama, K., et al. (2004). Porphyromonas gingivalis induces receptor activator of NFkappaB ligand expression in osteoblasts through the activator protein 1 pathway. Infect. Immun. 72, 1706-1714. doi: 10.1128/IAI.72.3.1706-1714.2004

O’Keefe, R. J., Teot, L. A., Singh, D., Puzas, J. E., Rosier, R. N., and Hicks, D. G. (1997). Osteoclasts constitutively express regulators of bone resorption: an immunohistochemical and in situ hybridization study. Lab. Invest. 76, 457-465.

Overturf, G. D. (1999). Infections and immunizations of children with sickle cell disease. Adv. Pediatr. Infect. Dis. 14, 191-218.

Pan, G., Ni, J., Yu, G., Wei, Y. F., and Dixit, V. M. (1998). TRUNDD, a new member of the TRAIL receptor family that antagonizes TRAIL signalling. FEBS Lett. 424, 41-45. doi: 10.1016/S0014-5793(98)00135-5

Pan, G., O’Rourke, K., Chinnaiyan, A. M., Gentz, R., Ebner, R., Ni, J., et al. (1997). The receptor for the cytotoxic ligand, TRAIL. Science 276, 111-113. doi: 10.1126/science.276.5309.111

Pesanti, E. L., and Lorenzo, J. A. (1998). Osteoclasts and effects of interleukin 4 in development of chronic osteomyelitis. Clin. Orthop. Relat. Res. 355, 290-299. doi: 10.1097/00003086-199810000-00031

Povolny, B. T., and Lee, M. Y. (1993). The role of recombinant human M-CSF, IL-3, GM-CSF and calcitriol in clonal development of osteoclast precursors in primate bone marrow. Exp. Hematol. 21, 532-537.

Priest, D. H., and Peacock, J. E. Jr. (2005). Hematogenous vertebral osteomyelitis due to Staphylococcus aureus in the adult: clinical features and therapeutic outcomes. South Med, J. 98, 854-862. doi: 10.1097/01.smj.0000168666.98129.33

Ray, K., Marteyn, B., Sansonetti, P. J., and Tang, C. M. (2009). Life on the inside: the intracellular lifestyle of cytosolic bacteria. Nat. Rev. Microbiol. 7, 333-340. doi: $10.1038 /$ nrmicro2112

Rosenshine, I., Ruschkowski, S., Foubister, V., and Finlay, B. B. (1994). Salmonella typhimurium invasion of epithelial cells: role of induced host cell tyrosine protein phosphorylation. Infect. Immun. 62, 4969-4974.

Sanchez, C. J. Jr., Ward, C. L., Romano, D. R., Hurtgen, B. J., Hardy, S. K., Woodbury, R. L., et al. (2013). Staphylococcus aureus biofilms decrease osteoblast viability, inhibits osteogenic differentiation, and increases bone resorption in vitro. BMC Musculoskelet. Disord. 14:187. doi: 10.1186/1471-247414-187

Sax, H., and Lew, D. (1999). Osteomyelitis. Curr. Infect. Dis. Rep. 1, 261-266. doi: 10.1007/s11908-999-0028-0

Schneider, P., Thome, M., Burns, K., Bodmer, J. L., Hofmann, K., Kataoka, T., et al. (1997). TRAIL receptors 1 (DR4) and 2 (DR5) signal FADD-dependent apoptosis and activate NF-kappaB. Immunity. 7, 831-836. doi: 10.1016/S10747613(00)80401-X

Scian, R., Barrionuevo, P., Fossati, C. A., Giambartolomei, G. H., and Delpino, M. V. (2012). Brucella abortus invasion of osteoblasts inhibits bone formation. Infect. Immun. 80, 2333-2345. doi: 10.1128/IAI.00208-12

Sinicrope, F. A., and Penington, R. C. (2005). Sulindac sulfide-induced apoptosis is enhanced by a small-molecule Bcl-2 inhibitor and by TRAIL in human colon cancer cells overexpressing Bcl-2. Mol. Cancer Ther. 4, 1475-1483. doi: 10.1158/1535-7163.MCT-05-0137

Smith, C. A., Farrah, T., and Goodwin, R. G. (1994). The TNF receptor superfamily of cellular and viral proteins: activation, costimulation, and death. Cell. 76, 959-962. doi: 10.1016/0092-8674(94)90372-7

Somayaji, S. N., Ritchie, S. L., Sahraei, M., Marriott, I., and Hudson, M. C. (2008). Staphylococcus aureus induces RANK-L and prostaglandin E2 expression in infected murine osteoblasts. Infect. Immun. 76, 5120-5126. doi: 10.1128/IAI.00228-08

Stashenko, P., Yu, S. M., and Wang, C. Y. (1992). Kinetics of immune cell and bone resorptive responses to endodontic infections. J. Endod. 18, 422-426. doi: 10.1016/S0099-2399(06)80841-1

Strober, W., Murray, P. J., Kitani, A., and Watanabe, T. (2006). Signalling pathways and molecular interactions of NOD1 and NOD2. Nat. Rev. 6, 9-20. doi: 10.1038/nril747

Suda, K., Woo, J. T., Takami, M., Sexton, P. M., and Nagai, K. (2002). Lipopolysaccharide supports survival and fusion of preosteoclasts independent of TNF-alpha, IL-1, and, RANKL. J. Cell. Physiol. 190, 101-108. doi: 10.1002/ jcp. 10041 
Suliman, A., Lam, A., Datta, R., and Srivastava, R. K. (2001). Intracellular mechanisms of TRAIL: apoptosis through mitochondrial-dependent and -independent pathways. Oncogene. 20, 2122-2133. doi: 10.1038/sj.onc.12 04282

Sutterwala, F. S., Ogura, Y., Szczepanik, M., Lara-Tejero, M., Lichtenberger, G. S., Grant, E. P., et al. (2006). Critical role for NALP3/CIAS1/Cryopyrin in innate and adaptive immunity through its regulation of caspase-1. Immunity. 24, 317-327. doi: 10.1016/j.immuni.2006.02.004

Takahashi, N., Udagawa, N., Akatsu, T., Tanaka, H., Shionome, M., and Suda, T. (1991). Role of colony-stimulating factors in osteoclast development. J. Bone Miner. Res. 6, 977-985. doi: 10.1002/jbmr.5650060912

Teitelbaum, S. L., Tondravi, M. M., and Ross, F. P. (1997). Osteoclasts, macrophages, and the molecular mechanisms of bone resorption. J. Leukoc. Biol. 61, 381-388.

Tenover, F. C., Biddle, J. W., and Lancaster, M. V. (2001). Increasing resistance to vancomycin and other glycopeptides in Staphylococcus aureus. Emerging Infect. Dis. 7, 327-332. doi: 10.3201/eid0702.010237

Thammasitboon, K., Goldring, S. R., and Boch, J. A. (2006). Role of macrophages in LPS-induced osteoblast and PDL cell apoptosis. Bone. 38, 845-852. doi: 10.1016/j.bone.2005.10.013

Ting, J. P., and Davis, B. K. (2005). CATERPILLER: A novel gene family important in immunity, cell death, and diseases. Annu. Rev. Immunol. 23, 387-414. doi: 10.1146/annurev.immunol.23.021704.115616

Tucker, K. A., Reilly, S. S., Leslie, C. S., and Hudson, M. C. (2000). Intracellular Staphylococcus aureus induces apoptosis in mouse osteoblasts, FEMS Microbiol Lett. 186, 151-156. doi: 10.1111/j.1574-6968.2000.tb09096.x

Ulett, G. C., and Adderson, E. E. (2005). Nitric oxide is a key determinant of group B streptococcus-induced murine macrophage apoptosis. J. Infect. Dis. 191, 1761-1770. doi: 10.1086/429693

Ulett, G. C., and Adderson, E. E. (2006). Regulation of Apoptosis by Gram-Positive Bacteria: Mechanistic Diversity and Consequences for Immunity. Curr Immunol Rev. 2, 119-141. doi: 10.2174/157339506776843033

Vitovski, S., Phillips, J. S., Sayers, J., and Croucher, P. I. (2007). Investigating the interaction between osteoprotegerin and receptor activator of NF-kappaB or tumor necrosis factor-related apoptosis-inducing ligand: evidence for a pivotal role for osteoprotegerin in regulating two distinct pathways. J. Biol. Chem. 282, 31601-31609. doi: 10.1074/jbc.M706078200

Wada, T., Nakashima, T., Hiroshi, N., and Penninger, J. M. (2006). RANKL-RANK signaling in osteoclastogenesis and bone disease. Trends Mol. Med. 12, 17-25. doi: 10.1016/j.molmed.2005.11.007

Walsh, M. C., and Choi, Y. (2003). Biology of the TRANCE axis. Cytokine Growth Factor Rev. 14, 251-263. doi: 10.1016/S1359-6101(03)00027-3

Wang, Y. H., Jiang, J., Zhu, Q., AlAnezi, A. Z., Clark, R. B., Jiang, X., et al. (2010). Porphyromonas gingivalis lipids inhibit osteoblastic differentiation and function. Infect. Immun. 78, 3726-3735. doi: 10.1128/IAI.00225-10

Widaa, A., Claro, T., Foster, T. J., O’Brien, F. J., and Kerrigan, S. W. (2012). Staphylococcus aureus protein A plays a critical role in mediating bone destruction and bone loss in osteomyelitis. PLoS ONE 7:e40586. doi: 10.1371/journal. pone.0040586
Wiggers, E. C., Johnson, W., Tucci, M., and Benghuzzi, H. (2011). Biochemical and morphological changes associated with macrophages and osteoclasts when challenged with infection. Biomed. Sci. Instrum. 47, 183-188.

Workman, M. R., Philpott-Howard, J., Bragman, S., Brito-Babapulle, F., and Bellingham, A. J. (1996). Emergence of ciprofloxacin resistance during treatment of Salmonella osteomyelitis in three patients with sickle cell disease. J. Infect. 32, 27-32. doi: 10.1016/S0163-4453(96)80006-5

Wright, J. A., and Nair, S. P. (2010). Interaction of staphylococci with bone. Int. J. Med. Microbiol. 300, 193-204. doi: 10.1016/j.ijmm.2009.10.003

Yamamoto, S., Mogi, M., Kinpara, K., Ishihara, Y., Ueda, N., Amano, K., et al. (1999). Anti-proliferative capsular-like polysaccharide antigen from Actinobacillus actinomycetemcomitans induces apoptotic cell death in mouse osteoblastic MC3T3-E1 cells. J. Dent. Res. 78, 1230-1237. doi: 10.1177/00220 345990780060601

Yoshii, T., Magara, S., Miyai, D., Nishimura, H., Kuroki, E., Furudoi, S., et al. (2002). Local levels of interleukin-1beta, $-4,-6$ and tumor necrosis factor alpha in an experimental model of murine osteomyelitis due to staphylococcus aureus. Cytokine 19, 59-65. doi: 10.1006/cyto.2002.1039

You, Z., Ouyang, H., Lopatin, D., Polver, P. J., and Wang, C. Y. (2001). Nuclear factor-kappa B inducible death effector domain-containing protein suppresses tumor necrosis factor-mediated apoptosis by inhibiting caspase- 8 activity. J. Biol. Chem. 276, 26398-26404. doi: 10.1074/jbc.M102464200

Young, A. B., Cooley, I. D., Chauhan, V. S., and Marriott, I. (2011). Causative agents of osteomyelitis induce death domain-containing TNF-related apoptosisinducing ligand receptor expression on osteoblasts. Bone. 48, 857-863. doi: 10.1016/j.bone.2010.11.015

Zhang, W., Ju, J., Rigney, T., and Tribble, G. (2013). Integrin $\alpha 5 \beta 1$-fimbriae binding and actin rearrangement are essential for Porphyromonas gingivalis invasion of osteoblasts and subsequent activation of the JNK pathway. BMC Microbiol. 13:5. doi: 10.1186/1471-2180-13-5

Conflict of Interest Statement: The author declares that the research was conducted in the absence of any commercial or financial relationships that could be construed as a potential conflict of interest.

Received: 04 September 2013; accepted: 04 December 2013; published online: 19 December 2013.

Citation: Marriott I (2013) Apoptosis-associated uncoupling of bone formation and resorption in osteomyelitis. Front. Cell. Infect. Microbiol. 3:101. doi: 10.3389/fcimb. 2013.00101

This article was submitted to the journal Frontiers in Cellular and Infection Microbiology.

Copyright (C) 2013 Marriott. This is an open-access article distributed under the terms of the Creative Commons Attribution License (CC BY). The use, distribution or reproduction in other forums is permitted, provided the original author(s) or licensor are credited and that the original publication in this journal is cited, in accordance with accepted academic practice. No use, distribution or reproduction is permitted which does not comply with these terms. 